\title{
Social discovery in an information abundant world: Designing to create capacity and seek solutions
}

\author{
Ben Shneiderman \\ University of Maryland, College Park, MD, USA \\ E-mail:ben@cs.umd.edu
}

\begin{abstract}
The first generation of search tools provided remarkable capabilities to many researchers for finding specific information, navigating to desired websites or tracking down needed documents. A second generation of tools is helping researchers conduct exploratory search in situations where the goals are less clear, where complete coverage is necessary, and where proof of absence is required (patents, legal precedents, etc.). However, the third generation of tools turns search into social discovery, in which colleagues, informal groups, companies, non-profit organizations, professional societies, and international federations are motivated to find, filter, organize, annotate and summarize voluminous information resources. The Reader-to-Leader framework describes the usability and sociability design features needed to motivate readers, contributors, collaborators and leaders. The Social Discovery framework, proposed in this paper, suggests that effective design enables people to engage in dialogs over weeks and months to create capacity (in the manner described by the Reader-to-Leader framework), and become more effective solution seekers. Much work remains to be done to validate these social discovery frameworks and refine them to fit diverse contexts.
\end{abstract}

Keywords: Social discovery, exploratory search, create capacity, seek solution, Reader-to-Leader Framework, participation, contribution, collaboration, motivation

\section{Introduction}

Traditional library patrons, who conscientiously scanned card catalogs and meticulously browsed the shelves to satisfy search goals, often succeeded in finding their desired facts or had the pleasure of making unexpected but fruitful discoveries. These library patrons may have thought their triumphs were the result of clever personal search strategies and solitary persistence. However, they were also beneficiaries of substantial social processes that created intellectual capabilities such as helpful indexing schemes, carefully assembled card catalogs and shelving strategies conducive to serendipitous browsing.

Some traditional library patrons may have made their search process social by engaging with knowledgeable reference librarians who steered them to the right location or even specific books. This form of social search did more than help single patrons who were seeking solutions to their information needs. The reference librarians learned about the range of patron interests, sometimes influencing collection management decisions, revising shelving strategies or promoting development of topic-specific finding aids.

By contrast, modern libraries have gone electronic in their catalogs and soon most books will be readable online. At the same time, the World-Wide Web provides an alternative source for information seekers with billions of web pages, documents and scientific articles, all indexed by Google, Bing, 
Yahoo and other services. Within those billions of web pages are carefully curated resources such as Wikipedia, newspaper resources such as the New York Times archives and the Open Directory. There are also community-generated resources such as billions of websites, blog posts, videos, photos and much more.

When modern library patrons or web searchers use computerized tools to satisfy their transactional, navigational or informational goals or engage in exploratory search, they are participating in rich social processes. The patrons benefit from domain experts and computer programmers, while contributing the data from their search process, which helps continuously improve search engine capabilities.

The community efforts to create capabilities may be more apparent to users of specialized thesauri from established organizations. For example, Westlaw's index of legal terms with more than 100,000 Key Number entries in a 23-level hierarchy (https://lawschool.westlaw.com/) or the National Library of Medicine's Medical Subject Headings (MeSH) with 26,000 descriptions and 177,000 entries (http://www.nlm.nih.gov/mesh/) were produced by substantial community processes.

Web-based information seekers are getting even more social in their search processes, with innovative strategies that support fact-finding as well as exploratory search. Now they are becoming increasingly collaborative. This article describes the shift from information-seeking theories that emphasize fact-finding to those that describe more open-ended exploratory search that often results in document, website or resource finding. However, the still more potent change is to promoting social discovery as an even more ambitious goal that is being realized by rapidly growing collaborative strategies for creating capacity and seeking solutions to significant problems.

The social discovery framework presented in this paper emphasizes the dual components of creating capability and seeking solutions. It makes manifest the growing importance of creating capacity by aggregating and cleaning data, organizing information and curating collections. Valuable contributions also come from those who tag, taxonomize, comment, annotate, rank, rate, review and summarize. Success over weeks and months is more likely if appropriate dialog is facilitated by well-designed user interfaces. These changes will accelerate if academic institutions, professional organizations and corporations can develop effective policies to motivate, recognize and reward those who create capacity and provide solutions.

\section{Evolution of information-seeking theories}

Early theorists, such as Bates [2,3], Kuhlthau [25], Marchionini [28] and Saracevic [42] described information-seeking as iterative multi-step processes that emphasized use of search systems for finding facts or information. For example, Marchionini [28] describes an eight step process:

(1) Recognize and accept an information problem.

(2) Define and understand the problem.

(3) Choose a search system.

(4) Formulate a query.

(5) Execute a search.

(6) Examine results.

(7) Extract information.

(8) Reflect, iterate, stop.

This model and others recognized that information seekers often consulted with colleagues as a primary source for asking and formulating queries, but the major effort was seen as solitary. Even later theories 
of information foraging [38] and visual analytics frameworks [50] focused on the solitary searcher, although the notion of presenting results to others became an increasing common goal.

The shift from finding facts to browsing knowledge [30] laid the foundation for the richer models of exploratory search [29,54-56] which addressed more complex issues, such as the need to learn more before appropriate queries could be posed. Asking good questions has long been recognized as deep intellectual and creative acts.

Exploratory search also deals with the situations in which goals are vaguer, metadata for indexing does not match the query, and early results may cause a mid-course correction towards new goals [59]. Descriptions of exploratory search were more likely to include social or collaborative processes, and dealt with more ambitious searches that might take days or weeks to complete. As researchers addressed more complex search goals, they identified the need to have complete searches such as in legal cases, patent discovery or medical diagnosis to ensure that every relevant case is found. Sometimes searchers also had the difficult task of conducting negative searches, to prove the absence of information such as patent searchers who must demonstrate the nonexistence of prior art.

The transition from exploratory to social search and then to bolder visions of social discovery had many contributors during the past two decades. Early researchers recognized that most information seekers discussed their information needs with familiar colleagues or asked questions of information specialists and domain experts. Early descriptions of technology mediation grew out of the computersupported collaborative work community, often building on emerging ideas of synchronous and asynchronous groupware and computer conferencing systems. These systems facilitated communication and collaboration among colleagues, small teams and moderate-sized groups, such as EIES [24] and Group Search [16].

The broadening of social search was advanced by Twidale, Nichols and Paice [51] who laid out a thoughtful taxonomy of many different ways that information seekers could activate social networks to gain assistance. They were inspired by small group social capabilities, often having a history of collaboration and an awareness who the contributors were, but they anticipated the possibilities for massive social participation that has emerged since that time.

The awareness that collaborations might expand from dozens to millions of people began to emerge, with credit going to Thomas $[48,49]$ who coined the phrase "million person communities". This idea was astonishing to members of ten-thousand person distribution lists who were already overwhelmed and struggled to envision million person communities. But even then, online business systems such as NASDAQs computerized stock trading system satisfied some definitions of communities, in that it was a bounded group of people with a clear common purpose and the actions of a small group of individuals could have large impacts on the entire community. While stock trades are a different kind of social participation, the lively discussions that triggered rapid price changes often occurred in external chat rooms, blogs, websites and public media. Also at that time, the Ebay community of buyers and sellers might have fit the definition of a million-person community since seller reputations were public, merchandise was searchable, auctions were visible to all and discussions were spirited.

The larger notion of social environments with millions of users was given a further boost by Brown and Duguid's widely-read book The Social Life of Information [6]. They complained about perceptions of information as a computerized commodity and promoted a social vision of situated contextualized information that emerged from conversations and social encounters. They helped shift the conversation from technology capabilities to social theory and raised questions about what metrics would help understand this new social environment. 
The notions of aggregating the small efforts of many users gained momentum as the World-Wide Web became actively used by professionals and discretionary users. Search systems such as Google were based on the PageRank algorithm that identified valuable web pages by the number and importance of other web pages that linked to them. Tagging of web pages, news stories, scientific articles and photos became common activities on websites such as Digg, del.icio.us and Connotea. Recommender systems expanded from consumer topics such as movies and music to scholarly efforts to identify relevant journals, documents and researchers.

At the same time the shift from professional-generated content to user-generated content dramatically increased the volume of information on the web and the need to organize it so that valuable materials could be found among the lesser contributions. E-commerce entrepreneurs also saw the opportunity to invite customers to tag, rate, rank and review commercial products, books, hotels, restaurants, services and anything else on the web.

\section{Emerging theories and frameworks}

The astonishing willingness of people to contribute in varied contexts is far from being understood. However, it is apparent that giving individuals a chance to be heard is generating billions of small contributions that help organize and rank information, consumer goods, scientific documents and any other materials that users find valuable. The remarkable success of Wikipedia demonstrated beyond most people's expectations (even the developers), the willingness of many people to participate in constructing a valuable community resource. The innovative social structure of Wikipedia dealt with many difficult problems, producing a successful model that others can draw on and alter to meet the needs of fresh contexts.

Motivational theories abound including the thoughtful analysis of Batson, Ahmad and Tseng [4] to describe the roles of egoism (for your own benefit), altruism (for the benefit of someone else), collectivism (for the benefit of a group or community) and principlism (adherence to a social norm that encourages contributions to community efforts). Others such as Nov [35], who studied Wikipedia contributors found that their major motivation was fun.

One way of understanding Wikipedia's success is by way of the Reader-to-Leader framework, which was based on studying 100+ empirical studies of participatory systems [40] (Fig. 1). The Reader-toLeader framework describes the design strategies that have been successful for improving usability and sociability, the tightly interwoven notions of user interfaces and emergent behavioral norms plus explicitly enforced policies. The first stage is to gain readers, which is accelerated by having excellent frequently updated content, strong public awareness promoted by enthusiastic users, low barriers to entry that ensure privacy and comprehensible universally usable user interfaces. Then converting readers to contributors requires a new set of usability and sociability design features, such as low threshold for first time users (no login required to make edits), high ceiling of powerful features for regular contributors, visible recognition for high quality and high quantity contributions and opportunities to see comments and suggestions.

Even with the good design in Wikipedia only 1 in a 1000 readers registers to become a named contributor, but this is enough to create a vibrant community which is apparent online and at the lively Wikimania conferences. Most contributors work on their own, but a small number engage with others to become collaborators who plan major additions or work together to create a high quality article on a controversial topic, often with the goal of gaining recognition as the "featured" article of the day. Finally, 


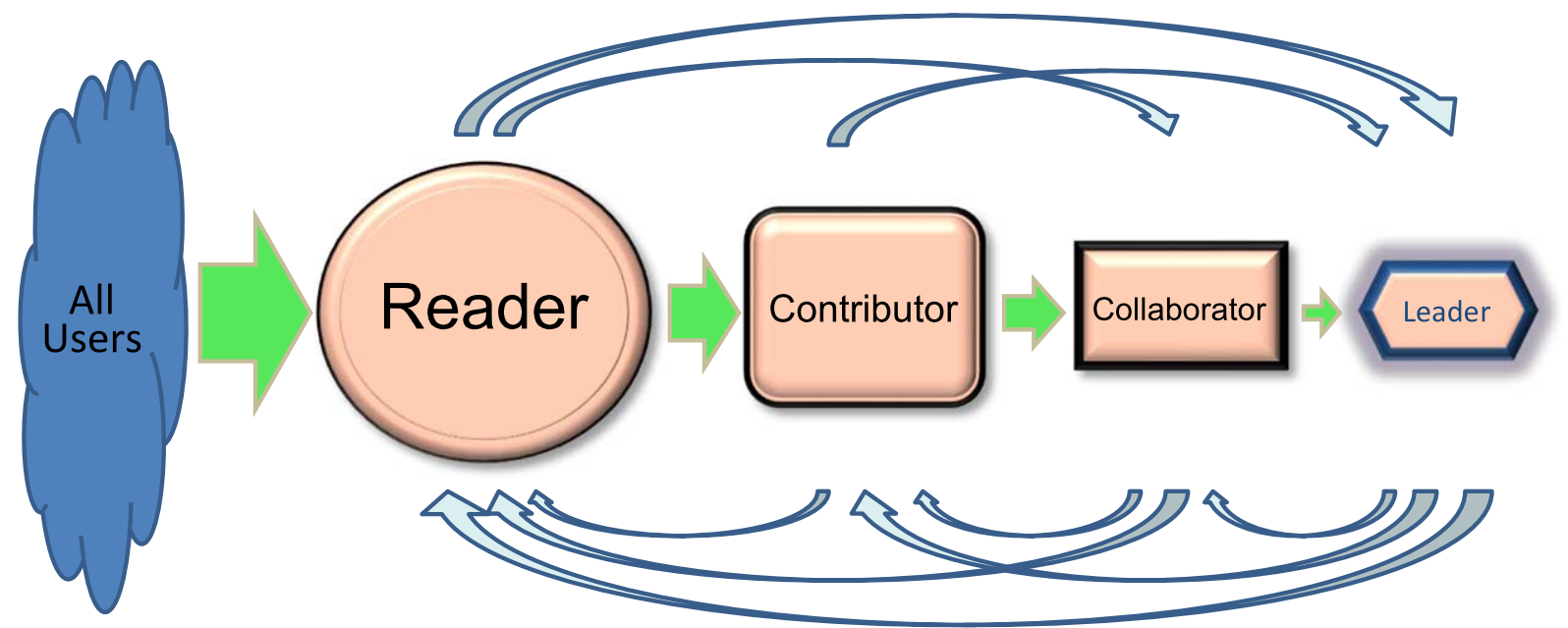

Fig. 1. The Reader-to-Leader framework suggests that the typical path for social media participation moves from reading online content to making contributions, initially small edits, but growing into more substantive contributions. The user-generated content can be edits to a wiki, comments in a discussion group, ratings of movies, photos, music, animations or videos. Collaborators work together over periods of weeks or months to make more substantial contributions, and leaders act to set policies, deal with problems, and mentor new users [40]. (Colors are visible in the online version of the article; http://dx.doi.org/10.3233/ISU-2011-0628.)

a still smaller number of participants become involved as leaders who make key policy decisions, deal with problems such as vandalism, mentor newcomers and set ambitious new goals. Charismatic leaders are often vital to the success of social and political systems, but they learn the limits of their powers and understand how to win over other users to build consensus for action. The Reader-to-Leader framework needs validation and refinement, but it provides one foundation for thinking about design issues to promote participation that supports social discovery. Alternate analyses provide other insights [7,26,39].

Dozens of other theories and frameworks have been proposed about how social media designs catalyze community contributions. These derive from social and political theories, as well as the experience of community builders and business entrepreneurs.

More recent analyses of social search, collaborative systems, exploratory search and social discovery have advanced understanding of what works and what does not. Corporate research groups have been strong leaders such as the Augmented Social Cognition group at the Palo Alto Research Center [9-12]. Other companies have also been active including Microsoft [1,12,33], HP Labs [14], IBM [31,32] and FX Palo Alto Labs [37].

Hearst's book [21] summarizes some of the social search strategies, and this paper goes further by offering a framework for enabling individual contributions, small teams engaged in collaborative search, and the more ambitious projects of communities. While social search emphasizes traditional information seeking, social discovery is a more ambitious concept, which is to make significant discoveries based on the results of search plus community problem solving.

A significant discovery is more than an individual finding a new restaurant or rediscovering a relationship between toxic chemical releases and cancer rates. In its most ambitious form social discovery is the detection of new and important relationships, patterns or principles that advance disciplines and make valuable contributions to society. This is a lofty aspiration, but there are already examples, especially from citizen science projects that demonstrate how collective efforts lead to important discoveries 


\begin{tabular}{|l|l|l|}
\hline $\begin{array}{c}\text { Social } \\
\text { Discovery }\end{array}$ & Create Capacity & Seek Solutions \\
\hline $\begin{array}{l}\text { Initiate } \\
\text { Requests }\end{array}$ & $\begin{array}{l}\text { Assemble thesauri } \\
\text { Collate catalogs } \\
\text { Aggregate information } \\
\text { Curate collections }\end{array}$ & $\begin{array}{l}\text { Ask questions } \\
\text { Offer challenge } \\
\text { Desire collaboration } \\
\text { Seek experts }\end{array}$ \\
\hline $\begin{array}{l}\text { Provide } \\
\text { Responses }\end{array}$ & $\begin{array}{l}\text { Tag/taxonomize } \\
\text { Comment/annotate } \\
\text { Rank/rate/review } \\
\text { Summarize }\end{array}$ & $\begin{array}{l}\text { Give answers } \\
\text { Respond to challenge } \\
\text { Discuss alternatives } \\
\text { Offer advice }\end{array}$ \\
\hline
\end{tabular}

Fig. 2. The Social Discovery framework describes the two stages of work: creating capacity and seeking solutions. These are carried out by a dialog between those who initiate requests and those who provide responses over a period of weeks and months. (Colors are visible in the online version of the article; http://dx.doi.org/10.3233/ISU-2011-0628.)

(www.citizensciencealliance.org). The social discovery concept extends the ideas from the creativity and discovery support tools based on information visualization, team coordination and design tools [45,52].

Creative contributions or important discoveries are typically made by an individual or a team working together, but increasingly the attribution of discoveries is being made to larger groups. Breakthroughs typically come from persistent devotion to a topic, developing domain knowledge, understanding relationships and pursuing meaningful goals. The literature on creativity has emphasized the individual, but there is an increasing awareness that teams and communities are extremely effective, especially as they bring complementary domain knowledge and varying problem-solving approaches. The social discovery framework in this paper proposes that designers can channel their work into facilitating individuals and communities to create capacity and seek solutions (Fig. 2).

Examples of current approaches provide inspiration and evidence that social discovery tools can be successful. Tagging (digg, del.icio.us, connotea) has become a common practice which benefits individuals in re-finding relevant material while helping the community to be aware of materials that they did not know about. This approach works on the large scale of flickr photos or the Steve.museum project for tagging art and cultural artifacts [13]. Ratings on Amazon and Netflix help other users find high quality items, while ratings of scientific papers or findings are yet to become widely used, but download and citation counts provide other evidence to filter the large volume of materials. Reviews of books, films, restaurants, hotels and consumer products are widespread but scientific reviews are typically embedded in research papers when they comment previous work. Some innovative systems extract these reviews and make them accessible to researchers [15]. Scientific publications have also become more open to social processes, as many journals invite discussions for each paper and sometimes require authors to publish their data so others can make new analyses. An ambitious project is to embed the data and the tools to analyze them in links from the articles, with a promise to preserve the data and update the tools [46]. The Reader-to-Leader framework suggests how to increase the motivation of individuals to contribute to these forms of capacity creation.

Organizations, especially professional societies, national libraries and publishers, have strong motivations to create capabilities such as thesauri, catalogs, finding aids and other guides to literature. They also aggregate information, clean the data and help organize materials for future users who are seeking information that facilitates their process of seeking solutions. Organizations also provide value by preserving these resources over long time periods and curate collections in ways that serve their users. Open Government efforts are aligned with this concept, since they are creating capabilities by making high-value 
data available for researchers, citizen groups and political analysts [5]. This social discovery framework (Fig. 2) focuses on information resources, but organizations also provide valuable capabilities in the form of software tools, user interfaces and information visualizations.

When individuals seek solutions they can begin by collecting information from these existing resources, but often they will need information from unfamiliar domains. Sometimes they can learn enough about the novel domain, but often finding a collaborator greatly accelerates their work. Collaborations have many other advantages such as keeping motivation high, but they also can have disadvantages such as disagreements about how to work together, share resources and apportion credit. Designers of online services need to understand these problems so as to promote trust and empathy, which increase the motivation to collaborate. Some approaches for individuals to seek solutions socially are as simple as sending an email message to a colleague or group, however, new technologies enable questions to be asked to millions of people. For example, New York Times technology reporter David Pogue regularly asks his 1.3 million Twitter followers questions that give him insights and evidence for articles. Two recent tweets asked: "Anyone had any great or bad experiences with Groupon, LivingSocial, BuyWithMe, BloomSpot, GiltCity, CrowdSavings? let me know" and "Can anyone link me to some early iPad reviews that predicted its doom? Thanks, Team Crowdsource! :)".

Free services for asking questions include YAHOO! Answers and Wikia Answers which allow posting questions, responding to questions, and searching through previous responses. AllExperts and a newer service called Quora emphasize the participation of identified experts, giving them a chance to become more prominent and to inform others. Google Answers, a fee for service site, has closed its operation, but fee services for reference searching are still available $[19,20]$. Other tools facilitate search for answers or discovery of experts from blog resources [22].

Organizations that seek solutions can post questions to a growing array of services that are attempting to help organizations solve their problems by way of crowd sourced solutions. Amazon's Mechanical Turk provides a marketplace by which organizations can pay modest amounts for the contributions of thousands of individuals to solving large problems. This works best for problems in which work can be subdivided into small efforts and where quality control can be applied to deal with poorer responses. Innocentive's website enables companies to post difficult problems and offer fees that are typically in the $\$ 10,000-100,000$ range, but sometimes go higher. Respondents submit their solutions and companies then review to decide if the solution warrants the award. Government agencies have also become generators of public challenges beginning with the District of Columbia Apps for Democracy project, which has influenced similar projects and cities and states in the US and beyond. Recently the US Government has opened the Challenge.gov website to engage citizens in providing solutions for government problems with awards ranging from a few thousands of dollars to millions of dollars. The less than one hundred challenges currently posted is likely to grow substantially as the awareness grows and methods are refined. Government agencies have long sought reviews and comments on grant proposals and proposed regulatory reforms, but these discussions are now becoming more public and expanding to new areas such as patent reviews [36]. In fact the entire Open Government Directive that stresses transparency, participation and collaboration can be seen as a large experiment in social discovery [5].

Certainly, other approaches will be developed by innovative researchers and entrepreneurs. A fascinating effort is the PatientsLikeMe website which invites people with chronic diseases to post a detailed record of their treatments, side effects and outcomes on a public website. By having an openness policy instead of a privacy policy, the developers of this site have engaged patients to provide medical information that helps patients make better decisions and clinical researchers pursue significant discoveries. 
The quick response to a search request from an individual or even the chat exchanges during social search are vastly different from the social discovery dialog that unfolds over weeks and months, between those who initiate requests and those who provide responses. Both sides learn from the early exchanges, refine their goals, broaden their circles and, if all goes well, eventually achieve consensus, common ground, shared insights or collaborative breakthroughs $[8,58]$. Social discovery is complex and varied, but potentially powerful. Designing to motivate participation and reward contributions will be a central challenge for the coming decades.

\section{Analytic tools to study social discovery}

Studying social discovery patterns will spawn new research methods and tools. Central to this endeavor will be social network analysis to understand the members and activities of participating communities, plus how their relationships change over time. For the first time in history, researchers will have access to huge volumes of log data recording the actions and relationships of participants in massive social processes. Our work has been directed at developing an open source tool, NodeXL (www.codeplex.com/nodexl) that collects and cleans social network data and then enables users to perform analyses such as computing metrics and forming clusters. These analysis tools are complemented by a variety of layout algorithms that provides users with many choices for placement, color/size/shape coding, and filtering to reveal important patterns, clusters, gaps, anomalies and outliers [18].

One recent NodeXL application was to study the patterns of cooperation among the 988 organizations that compile and share data on biodiversity (Fig. 3). Some organizations, like the Avian Knowledge Network (AKN) are specialized; others, like the Encyclopedia of Life (EOL), study all forms of life. Vertex size is mapped to degree, so that larger vertices (NCBI, GBIF) share data with more organizations than smaller vertices. These large vertices play a valuable role in the network by bringing in data from a range of sources. Organizations that collaborate with many key players (Encyclopedia of Life, www.EOL.org) also play an important role, acting as liaisons between groups that would not otherwise share data.The black dots in the lower right hand corner represent an additional 625 organizations that gather important data on biodiversity but do not yet share data with anyone else in the network. The managers of the Encyclopedia of Life project and its partners are targeting these organizations for future collaboration.

\section{Conclusions}

The ideas in this paper promote thinking about and conducting research into the mechanisms that facilitate social discovery, which is defined as the collaborative processes that promote creating capabilities and seeking solutions. Social discovery processes are becoming common for individuals seeking personal information as well as communities of people who collaborate over time on ambitious projects. The implications are profound for academic, industrial and government researchers, since they force reconsideration of reward structures, especially for creating capabilities, which deserve more recognition in tenure or promotion reviews. Can a molecular biologists add to their tenure cases by curating genomic datasets, an astronomers be promoted because they engaged a million citizen scientists to taxonomize galaxies? New interface designs and interactive visualizations will dramatically increase the potential for social discovery while creating capabilities and seeking solutions. These new directions open vast research opportunities. 


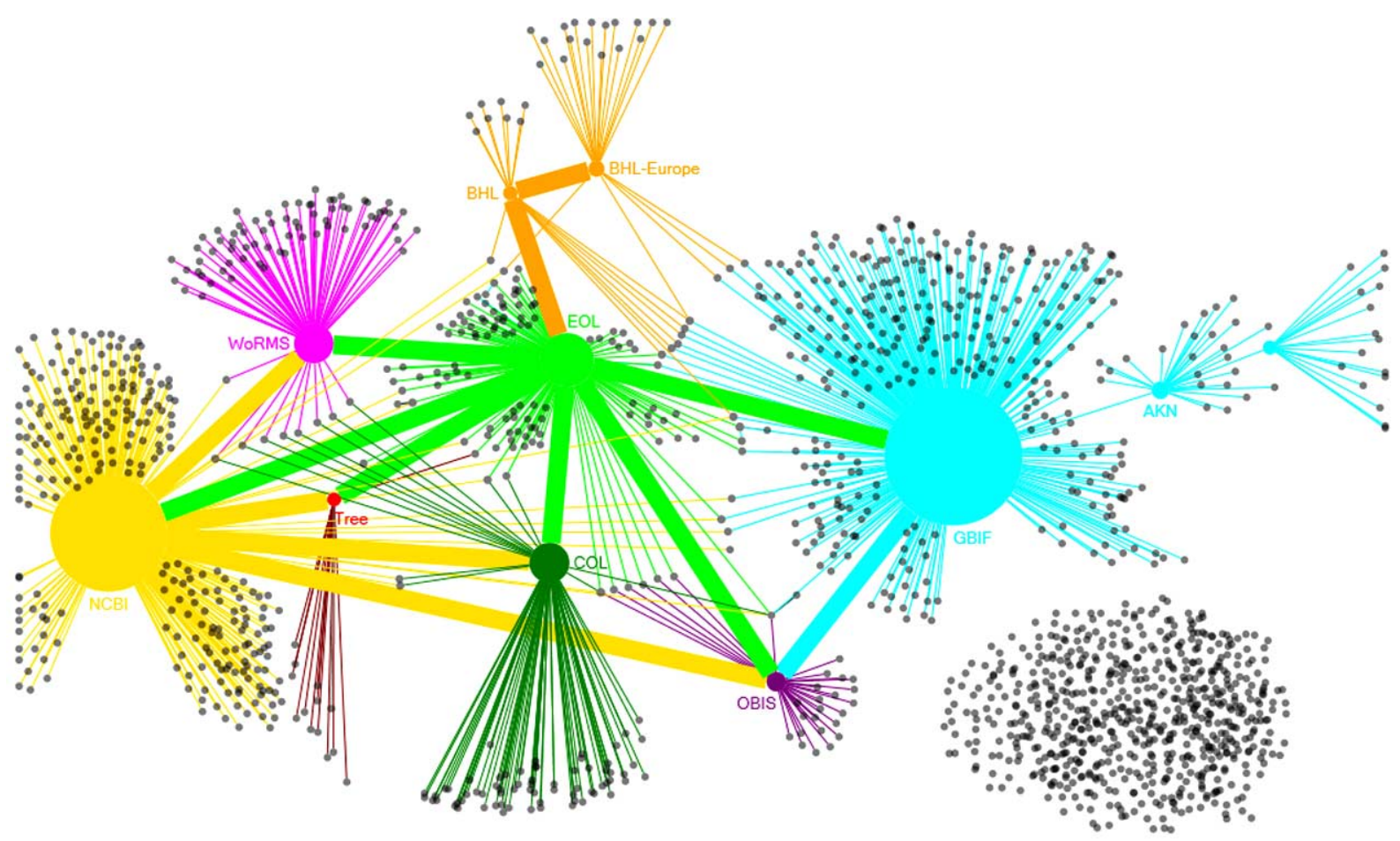

Created ty NodeXL

Fig. 3. The collaboration networks among 988 organizations who compile and share data on biodiversity. This figure was generated by Derek Hansen and Ann Bowser using NodeXL (www.codeplex.com/nodexl). (Colors are visible in the online version of the article; http://dx.doi.org/10.3233/ISU-2011-0628.)

\section{Acknowledgements}

I greatly appreciate the NFAIS community for recognizing my work with the Miles Conrad Award. My original award lecture on February 28, 2011 during the NFAIS annual conference in Philadelphia helped shape my ideas, which I led to this paper. I appreciate the partial support of National Science Foundation grants SBE-0915645 TLS: Science \& Technology Innovation Concept Knowledge-base (STICK): Monitoring, Understanding, and Advancing the (R)Evolution of Science \& Technology Innovations, and IIS-0956571, Two NSF Workshops: Technology-Mediated Social Participation. Thanks to Sue Dumais, Derek Hansen, and Gary Marchionini for comments on early drafts.

\section{References}

[1] S. Amershi and M.R. Morris, CoSearch: a system for co-located collaborative web search, in: Proc. SIGCHI Conference on Human Factors in Computing Systems (CHI'08), ACM New York, NY, USA, 2008, pp. 1647-1656.

[2] M.J. Bates, Subject access in online catalogs: a design model, Journal of the American Society for Information Science 37(6) (1986), 357-376.

[3] M.J. Bates, The design of browsing and berrypicking techniques for the online search interface, Online Review 13 (1989), 407-424.

[4] C.D. Batson, N. Ahmad and J. Tsang, Four motives for community involvement, Journal of Social Issues 58 (2002), 429-445. 
[5] J.C. Bertot, P.T. Jaeger, S. Munson and T. Glaisyer, Engaging the public in open government: social media technology and policy for government transparency, IEEE Computer 43(11) (2010), 60-67.

[6] J.S. Brown and P. Duguid, The Social Life of Information, Harvard Business School Press, Boston, MA, 2000.

[7] S.L. Bryant, A. Forte and A. Bruckman, Becoming Wikipedian: transformation of participation in a collaborative online encyclopedia, in: Proc. ACM GROUP'05, ACM Press, New York, 2005, pp. 11-20.

[8] Y. Chen, J. Yang and W. Ribarsky, Toward effective insight management in visual analytics systems, in: Proc. IEEE Pacific Visualization Symposium, IEEE Press, Piscataway, NJ, 2009, pp. 49-56.

[9] E.H. Chi, Augmented social cognition: using social web technology to enhance the ability of groups to remember, think and reason, in: Proc. 35th SIGMOD International Conference on Management of Data, ACM Press, New York, 2009, pp. 973-984.

[10] E.H. Chi, S. Munson, G. Fischer, S. Vieweg and C. Parr, Advancing the design of technology-mediated social participation systems, IEEE Computer 43(11) (2010), 29-35.

[11] B.M. Evans and E.H. Chi, Towards a model of understanding social search, in: Proc. ACM 2008 Conference on Computer Supported Cooperative Work, ACM Press, New York, 2008, pp. 485-494.

[12] B.M. Evans, S. Kairam and P. Pirolli, Do your friends make you smarter?: An analysis of social strategies in online information seeking, Information Processing and Management 46(6) (2010), 679-692.

[13] J. Golbeck, J. Koepfler and B. Emmerling, An experimental study of social tagging behavior and image content, Journal of the American Society for Information Science \& Technology 62(9) (2011), 1750-1760.

[14] S. Golder and B.A. Huberman, Usage patterns of collaborative tagging systems, Journal of Information Science 32(2) (2006), 198-208.

[15] R. Gove, C. Dunne, B. Shneiderman, J. Klavans and B. Dorr, Understanding scientific literature networks: an evaluation of action science explorer, Technical report, University of Maryland, 2011.

[16] S. Greenberg and M. Roseman, GroupWeb: a www browser as real time groupware, in: CHI Companion, ACM Press, New York, 1996, pp. 271-272.

[17] T. Hammond, T. Hannay, B. Lund and J. Scott, Social bookmarking tools (II): a general review, D-Lib Magazine 11(4) (2005).

[18] D. Hansen, B. Shneiderman and M.A. Smith, Analyzing Social Media Networks with NodeXL: Insights from a Connected World, Morgan Kaufmann, Boston, MA, 2011.

[19] F. Harper, D. Raban, S. Rafaeli and J. Konstan, Predictors of answer quality in online Q\&A sites, in: Proc. CHI 2008: Human Factors in Computing Systems, ACM Press, New York, NY, 2008, pp. 865-874.

[20] F. Harper, J. Weinberg, J. Logie and J. Konstan, Question types in social Q\&A sites, First Monday 15(7) (2010), available at: http://firstmonday.org/htbin/cgiwrap/bin/ojs/index.php/fm/article/view/2913/2571.

[21] M. Hearst, Search User Interface, Cambridge University Press, New York, 2009.

[22] M. Hearst, M. Hurst and S. Dumais, What should blog search look like?, in: Proc. ACM Workshop on Search in Social Media, ACM Press, New York, 2008, pp. 95-98.

[23] J. Heer, F.B. Viégas and M. Wattenberg, Voyagers and voyeurs: supporting asynchronous collaborative information visualization, Communications of the ACM 52(1) (2009), 87-97.

[24] S.R. Hiltz and M. Turoff, The Network Nation: Human Communication via Computer, Revised edn, MIT Press, Cambridge, MA, 1993.

[25] C.C. Kuhlthau, Inside the search process: information seeking from the user's perspective, Journal of the American Society for Information Science 42(5) (1991), 361-371.

[26] C. Li and J. Bernoff, Groundswell: Winning in a World Transformed by Social Technologies, Harvard Business Review, Boston, MA, 2008.

[27] B. Lund, T. Hammond, M. Flack and T. Hannay, Social bookmarking tools (II): a case study - Connotea, D-Lib Magazine 11(4) (2005).

[28] G. Marchionini, Information Seeking in Electronic Environments, Cambridge University Press, Cambridge, UK, 1995.

[29] G. Marchionini, Exploratory search: from finding to understanding, Communications of the ACM 49(4) (2006), 41-46.

[30] G. Marchionini and B. Shneiderman, Finding facts vs. browsing knowledge in hypertext systems, IEEE Computer 21(1) (1988), 70-80.

[31] D.R. Millen, J. Feinberg and B. Kerr, Dogear: social bookmarking in the enterprise, in: Proc. SIGCHI Conference on Human Factors in Computing Systems (CHI'06), ACM Press, New York, 2006, pp. 111-120.

[32] D.R. Millen, M. Yang, S. Whittaker and J. Feinberg, Social bookmarking and exploratory search, in: Proc. European Computer Supported Cooperative Work, L. Bannon, I. Wagner, C. Gutwin, R. Harper and K. Schmidt, eds, Springer, 2007, pp. 21-40.

[33] M.R. Morris, A survey of collaborative web search practices, in: Proc. SIGCHI Conference on Human Factors in Computing Systems (CHI'08), ACM Press, New York, 2008, pp. 1657-1660.

[34] M.R. Morris and E. Horvitz, SearchTogether: an interface for collaborative web search, in: Proc. Conference on User Interface Science and Technology, ACM Press, New York, 2007, pp. 3-12. 
[35] O. Nov, What motivates Wikipedians?, Communications of the ACM 50(11) (2007), 60-64.

[36] B. Noveck, Wiki Government: How Technology Can Make Government Better, Democracy Stronger and Citizens More Powerful, Brookings Institution Press, Washington, DC, 2009.

[37] J. Pickens, G. Golovchinsky, C. Shah, P. Qvarfordt and M. Back, Algorithmic mediation for collaborative exploratory search, in: Proc. 31st Annual International ACM SIGIR Conference on Research and Development in Information Retrieval (SIGIR'08), ACM Press, New York, 2008, pp. 315-322.

[38] P. Pirolli and S.K. Card, Information foraging, Psychological Review 106(4) (1999), 643-675.

[39] L. Porter, Designing for the Social Web, New Riders, Berkeley, CA, 2008.

[40] J. Preece and B. Shneiderman, The Reader-to-Leader framework: motivating technology-mediated social participation, AIS Transactions on Human-Computer Interaction 1(1) (2009), 13-32.

[41] A. Quinn and B. Bederson, Human computation: a survey and taxonomy of a growing field, in: Proc. SIGCHI Conference on Human Factors in Computing Systems (CHI2011), ACM Press, New York, 2011, pp. 1403-1412.

[42] T. Saracevic, The stratified model of information retrieval interaction: Extension and application, Proceedings of the American Society for Information Science 34 (1997), 313-327.

[43] B.M. Sarwar, J.A. Konstan, J. Herlocker, B. Miller and J. Riedl, Using filtering agents to improve prediction quality in the GroupLens research collaborative filtering system, in: Proc. ACM conference on Computer Supported Cooperative Work (CSCW'98), ACM Press, New York, 1998, pp. 345-354.

[44] B. Shneiderman, Leonardo's Laptop: Human Needs and the New Computing Technologies, MIT Press, Cambridge, MA, 2003.

[45] B. Shneiderman, Creativity support tools: accelerating discovery and innovation, Communications of the ACM 50(12) (2007), 20-32.

[46] E.R. Siegel, D.A.B. Lindberg, G.P. Campbell, W.G. Harless and C.R. Goodwin, Defining the next generation journal: the NLM-Elsevier interactive publications experiment, Information Services \& Use 30 (2010), 17-30.

[47] J. Teevan, D. Ramage and M.R. Morris, \#TwitterSearch: a comparison of microblog and web search, in: Proc. 4th Int'l Conference on Web Search and Data Mining, ACM Press, New York, 2011, pp. 35-44.

[48] J.C. Thomas, Facilitating global intelligence, IEEE Computer Graphics and Applications 19(6) (1999), 70-74.

[49] J.C. Thomas, An HCI agenda for the next millennium: emergent global intelligence, in: Frontiers of Human-Centered Computing, Online Communities and Virtual Environments, R. Earnshaw, R. Guedj, A. van Dam and J. Vince, (eds), Springer-Verlag, London, 2001.

[50] J.J. Thomas and K.A. Cook, eds, Illuminating the Path: Research and Development Agenda for Visual Analytics, IEEE Press, Piscataway, NJ, 2005.

[51] M. Twidale, D. Nichols and C. Paice, Browsing is a collaborative process, Information Processing and Management 33(6) (1997), 761-783.

[52] F. Viegas, M. Wattenberg, F. van Ham, J. Kriss and M. McKeon, ManyEyes: a site for visualization at internet scale, IEEE Transaction on Visualization and Computer Graphics 13(6) (2007), 1121-1128.

[53] M. Wattenberg and J. Kriss, Designing for social data analysis, IEEE Transactions on Visualization and Computer Graphics 12(4) (2006), 549-557.

[54] R.W. White, G. Marchionini and G. Muresan, Evaluating exploratory search systems, Information Processing and Management 44(2) (2008), 433-436.

[55] R.W. White, B. Kules, S.M. Drucker and M.C. schraefel, Supporting exploratory search, introduction to special section, Communications of the ACM 49(4) (2006), 36-39.

[56] R.W. White and R.A. Roth,Exploratory Search: Beyond the Query-Response Paradigm, Morgan and Claypool, San Rafael, CA, 2009.

[57] P. Wicks, M. Massagli, J. Frost, C. Brownstein, S. Okun, T. Vaughan, R. Bradley and J. Heywood, Sharing health data for better outcomes on PatientsLikeMe, Journal of Medical Internet Research 12(2) (2010), e19, available at: http://www.jmir.org/2010/2/e19/.

[58] W. Willett, J. Heer, J.M. Hellerstein and M. Agrawala, CommentSpace: Structured support for collaborative visual analysis, in: Proc. ACM Conf. on Human Factors in Computing Systems (CHI 2011), ACM Press, New York, 2011, pp. 31313140 .

[59] M.L. Wilson, B. Kules, M.C. Schraefel and B. Shneiderman, From keyword search to exploration: designing future search interfaces for the Web, Foundations and Trends in Web Science 2(1) (2010), 1-97. 